\title{
INVITRO COMPATIBILITY EVALUATION FOR THE BIOCONVERSION OF DOMESTIC SOLID WASTES BY MIXED CULTURES OF MICRO-ORGANISMS
}

\author{
Ashwitha Kodaparthi ${ }^{1}$, Pavan Kumar Pindi ${ }^{2}$, A. Swaroopa Rani ${ }^{3}$ \\ ${ }^{1}$ Department of Microbiology, Palamuru University, Mahabubnagar, A.P-502 319 \& Centre for Biotechnology, IST, \\ JNTUH, Hyderabad, A.P- 500085 \\ ${ }^{2}$ Associate Professor and HOD, Department of Microbiology, Palamuru University, Mahabubnagar, Andhra Pradesh \\ -509001, India \\ ${ }^{3}$ Centre for Biotechnology, IST, JNTUH, Hyderabad, A.P- 500085
}

\begin{abstract}
Among all the wastes, disposal of large amount of food waste is one of the most serious problems in cities. As food waste has high water content and decomposes readily, many unpleasant environmental consequences can arise during its storage, collection and transportation. The bioconversion of solid wastes into compost by microbial population can be proved as an efficient, ecofriendly, and cost effective solution for the management of solid wastes. The objective of this study was to evaluate in vitro compatibility of different microorganisms and to study the effect of successive microbial population on solid wastes for its successful bioconversion into compost. The most promising strategies for improving management of solid wastes have been identified as minimization of the amount of the solid. The composting process involves the controlled aerobic exothermic microbial decomposition. Saccharomyces cereviseae, Trichoderma viridae and Bacillus (PU7), accession number GU566359, isolated from rhizosphere of Sesbania grandiflora from Mahabubnagar $\left(16.4600^{\circ} \mathrm{N}, 77.5600^{\circ}\right.$ E), India, were selected for compatible/incompatible mixed cultures. Combinations of them were used to evaluate their potential performance as compatible/incompatible culture for microbial decomposition.
\end{abstract}

Keywords: Invitro compatibility, bioconversion, solid waste and microorganisms

\section{INTRODUCTION}

Bioconversion is a process of converting or changing an organic material into other useful products and has added value by taking advantage of events and the biosynthesis or the formation biolysis or solutions.

The treatment and disposal of wastes, which are mainly of organic origin, is one of the most important problems (Martin A.M., 1991) and greatest challenges facing mankind. Environmental degradation is often caused by mismanagement of wastes (Hart SA, 1977). Myles (Myles TG, 1997) wrote that humankind has progressed to the point of having numerous large organic waste streams, thus intensive decomposition systems to match our intensive production systems must be developed.

Solid wastes are inevitable in today's society. The collection and disposal of solid wastes is rapidly becoming one of the major unsolved problems of urban areas in India. Among all the wastes disposal of large amount of food waste generated daily is one of the most serious problems in cities. The most promising strategies for improving management of solid wastes have been identified as minimization of the amount of the solid wastes genera fed and maximization of waste recycling as well as resource recovery.
Yeasts: The yeast function as natural decomposers in the environment.

Trichoderma Viride: The fungus Trichoderma viride is a potential to produce cellulase in relatively large quantities in order to degrade cellulose. 


\section{Bacillus Palamurensis PU7:}
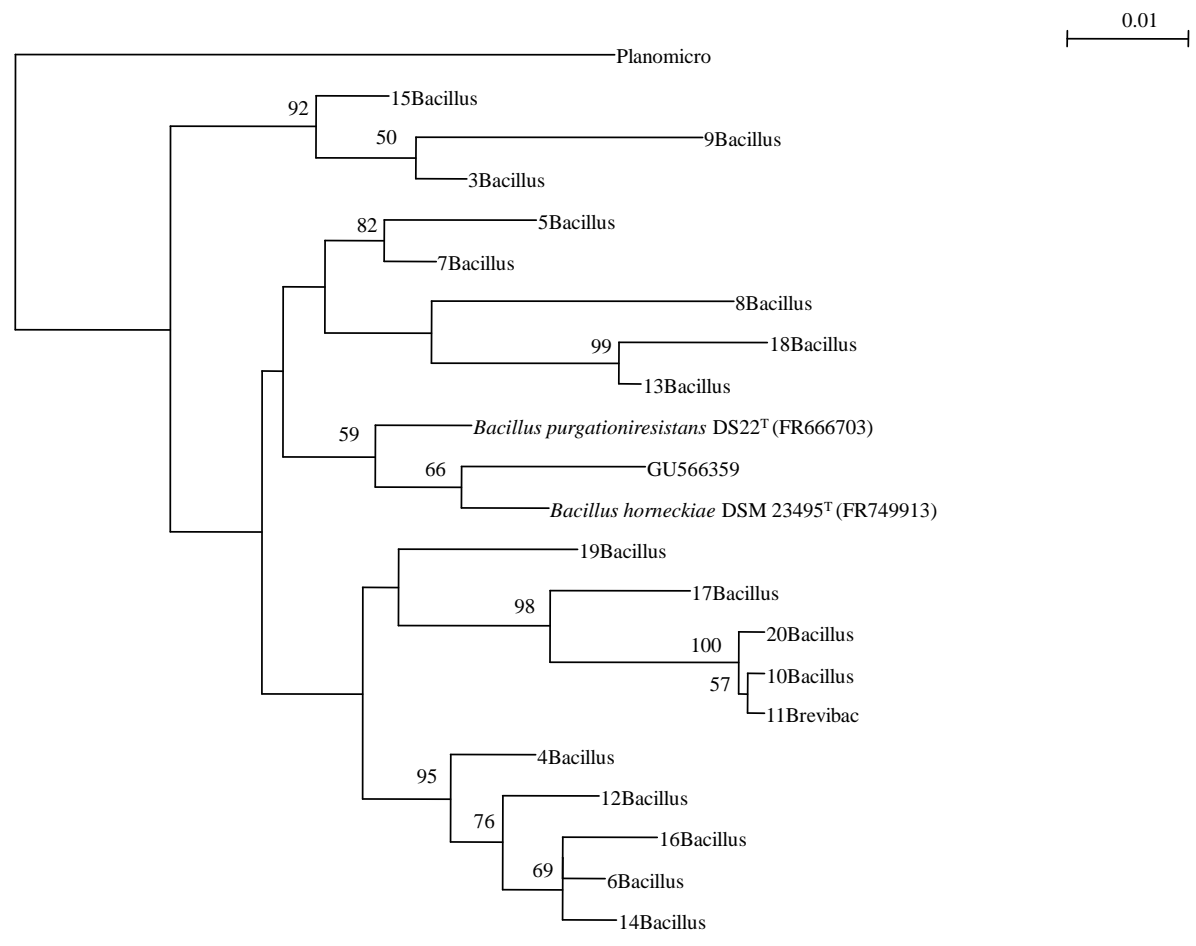

\section{MATERIALS AND METHODS}

The study aims at the evaluation of in vitro compatibility of different microorganisms and to study the effect of successive microbial population on solid wastes for its successful bioconversion into compost.

\subsection{Materials and Micro-organisms}

Kitchen wastes consisting of vegetable wastes, fruit wastes, coffee grounds, bread pieces and other household wastes. Pure culture of Saccharomyces cereviseae, Trichoderma viridae and Bacillus PU7 were used for the study.

\subsection{Culture Media and Condition}

Subculturing of Yeast: Yeast was subcultured in MGYP media at $\mathrm{pH}$ 6.4-6.8. $100 \mathrm{ml}$ of MGYP agar media was prepared, autoclaved and poured into petriplates. After solidification of media single colony of yeast from pure culture was taken and streaked. Plates were kept for incubation at $37^{\circ} \mathrm{C}$.

Subculturing of Bacillus PU7: Bacillus PU7 were subcultured in HIMEDIA Bacillus selection agar media adjusted to $\mathrm{pH} 5.7 .6 .97 \mathrm{gm}$ was suspended in $100 \mathrm{ml}$ of distilled water containing $0.132 \mathrm{ml}$ Glacial acetic acid. Media was heated with frequent stirring and was boiled for 1-2 min to dissolve the medium completely. Media was poured and solidified. Single colony of Bacillus inoculum was streaked. And plates were incubated at $37^{\circ} \mathrm{C}$.

Subculturing of Trichoderma viridae: Trichoderma viridae were subcultured in Potato dextrose media which was adjusted to $\mathrm{pH}$ of 5.5. Media was prepared, autoclaved and poured into plates. Inoculum was streaked and incubated at $37^{\circ} \mathrm{C}$.

Mass production of Microbial Cultures: Yeasts were cultured in MGYP medium at $\mathrm{pH}$ 6.4-6.8. Bacillus HIMEDIA adjusted to $\mathrm{pH} 5.7$ was used to culture Bacillus PU7. Trichoderma viridae were cultured in Potato dextrose media adjusted to $\mathrm{pH}$ 5.5. Conical flask containing each of $200 \mathrm{ml}$ media for each respected microbial cultures were plugged with cotton and sterilized at $15 \mathrm{lbs}$ for 20 minutes. Each flask was inoculated with their respective cultures. These flasks were incubated at room temperature for four days on an orbital shaker.

Counting of micro-organisms: The growth of Yeast, Trichoderma viridae and Bacillus PU7 were measured by spread plate counting method. $1 \mathrm{ml}$ of inoculum was suspended in $9 \mathrm{ml}$ of sterile distilled water and mixed for 5 min. The suspension was then serially diluted and spread onto agar plate media. Yeast was counted on MGYP agar after 2-3 days of incubation at $37{ }^{\circ} \mathrm{C}$. Lactobacilli were counted on MRS agar media after 4-5 days of incubation at $30{ }^{\circ} \mathrm{C}$. Trichoderma viridae were counted on Potato dextrose agar media after 2-3 days of incubation at $37^{\circ} \mathrm{C}$.

In vitro compatibility evaluation of Micro-organisms: Saccharomyces cereviseae, Trichoderma viridae and Bacillus PU7 were grown in the same conical flask in their respective culture media Potato dextrose Broth, MGYP and MRS. Four different combinations S/L, S/A, L/A and S/L/A were studied. Conical flasks containing media were inoculated and incubated at room temperature for four days 
on an orbital shaker. The growth of all these combinations were measured by spread plate counting method. Serial dilution was done and total viable count was taken out. The combination of S/A were counted on Potato dextrose agar media after 2-3 days of incubation at $30{ }^{\circ} \mathrm{C}$. The combinations of S/L were counted on MGYP media after 45 days of incubation at $30^{\circ} \mathrm{C}$. The combination of L/A were counted on Potato dextrose agar after 4-5 days of incubation of $30^{\circ} \mathrm{C}$. All microbial combinations were also grown in the same Petri dish few $\mathrm{cm}$ apart in their respected media, Potato dextrose agar, MGYP agar and MRS agar and were incubated at $30^{\circ} \mathrm{C}$. Four different in vitro interactions were studied and summarized according to some possible outcomes, i.e. mutual intermingling, partial mutual intermingling and inhibition at contact point.

Lab-Scale composting: A lab-scale composting was conducted using compatible mixed culture of S/A, A/L, S/L and S/L/A. Cultures bottles containing $50 \mathrm{gm}$ of homogenized wastes was inoculated with $1 \mathrm{ml}$ of each microbial combination. Control and sterilized set of samples were also used for comparison of rate of decomposition. Bottles were kept with loosened cap to allow aerobic condition and incubation was done at room temperature. The composting material was agitated once daily.

\section{RESULTS}

Organic waste is not only the result of human activity. Recycling of organic waste is thus an integrated function of any ecosystem. Composting is a process in which the naturally occurring ability of organism to recycle organic waste is used for the benefit of humans in an accelerated degradation of organic waste. Microbes are the drivers which accelerate the decomposition process. This reason makes the use of microbes for their compatibility testing. In this study the interaction between Saccharomyces cereviseae, Trichoderma viridae and Bacillus PU7 were investigated for compatible/incompatible mixed culture which will help in acceleration of bioconversion of domestic solid waste in to compost.

\subsection{Microbial Growth Interaction in Single and}

\section{Mixed Culture Broth}

Yeast grown in single culture broth reaches maximum density of $39.7 * 10^{7} \mathrm{cfu} / 1 \mathrm{ml}$. The culture of Bacillus grown singly were found to be $3.36 * 10^{7} \mathrm{cfu} / 1 \mathrm{ml}$. Trichoderma viridae was found to be $4.29 * 10^{7} \mathrm{cfu} / 1 \mathrm{ml}$ (table: 1 ) When combinations of mixed cultures were counted for their total viable count, it was found that in mixed culture of yeast and Trichoderma viridae the total viable count of yeast was $15.5^{*} 10^{7} \mathrm{cfu} / 1 \mathrm{ml}$ and Trichoderma viridae was $4.14 * 10^{7}$ $\mathrm{cfu} / 1 \mathrm{ml}$. this result shows that there was declination in the count of yeast and Trichoderma viridae in mixed culture, but there was not dominancy of any one colony in comparison with the other one. Both colonies were mutually growing. Total viable count of mixed cultures of Bacillus and Trichoderma were found to be $5.01 * 10^{7} \mathrm{cfu} / 1 \mathrm{ml}$, and $6.43 * 10^{7} \mathrm{cfu} / 1 \mathrm{ml}$. This result suggested that count of yeast colony decreases but Bacillus count remain the same in mixed culture without hampering each other. Count of mixed culture of Trichoderma, Bacillus and yeast were found to be $6.48 * 10^{7} \mathrm{cfu} / 1 \mathrm{ml}, 4.91 * 10^{7} \mathrm{cfu} / 1 \mathrm{ml}$ and $8.86 * 10^{7} \mathrm{cfu} / 1 \mathrm{ml}$ (table 2).

Table 1: Total viable count of micro-organisms in single culture

\begin{tabular}{|l|l|}
\hline Micro-organism & $\begin{array}{l}\text { Colony forming unit/ } \\
\text { 1ml }\end{array}$ \\
\hline Trichoderma viridae (T) & $4.29 * 10^{7}$ \\
\hline $\begin{array}{l}\text { Saccharomyces } \\
\text { cereviseae (S) }\end{array}$ & $39.7^{*} 10^{7}$ \\
\hline Bacillus PU7 (B) & $3.36^{*} 10^{7}$ \\
\hline
\end{tabular}

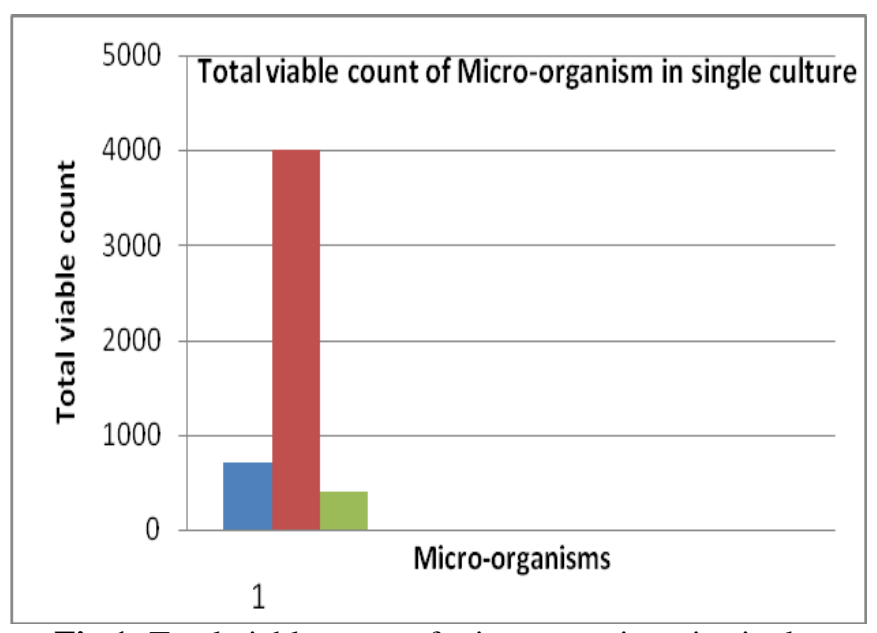

Fig 1: Total viable count of micro-organisms in single culture

Table 2: Total viable count of micro-organisms in mixed culture

\begin{tabular}{|l|l|}
\hline Combination of mixed Cultures & $\begin{array}{l}\text { Colony forming } \\
\text { unit/ 1ml }\end{array}$ \\
\hline $\begin{array}{l}\text { Saccharomyces cereviseae } \\
\text { Trichoderma viridae }\end{array}$ & $14.5^{*} 10^{7}+4.14 * 10^{7}$ \\
\hline $\begin{array}{l}\text { Saccharomyces cereviseae + } \\
\text { Bacillus PU7 }\end{array}$ & $3.75 * 10^{7}+6.64 * 10^{7}$ \\
\hline $\begin{array}{l}\text { Bacillus PU7 + Trichoderma } \\
\text { viridae }\end{array}$ & $5.01 * 10^{7}+6.43^{*} 10^{7}$ \\
\hline $\begin{array}{l}\text { Saccharomyces cereviseae }+ \\
\text { Bacillus PU7 + Trichoderma } \\
\text { viridae }\end{array}$ & $\begin{array}{l}6.48^{7} 10^{7}+8.86^{*} 10^{7} \\
+40^{7}\end{array}$ \\
\hline
\end{tabular}




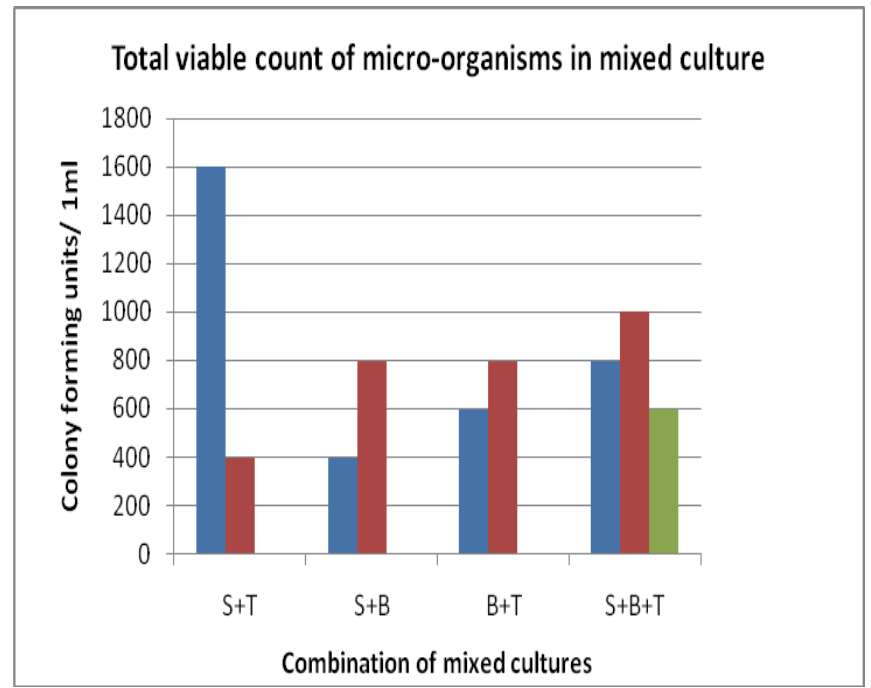

Fig 2: Total viable count of micro-organisms in mixed culture

\subsection{In Vitro Compatibility Analysis in Agar Media}

In order to better understand the interactions that occur between Saccharomyces cereviseae, Bacillus PU7 and Trichoderma viridae, different in vitro interactions were studied. Yeast, Bacillus and Trichoderma were grown in same Petri dish in their respective media Potato dextrose agar. Malt extract glucose yeast extracts peptone agar and MRS agar media. The interaction between Yeast and Trichoderma were found to be mutual intermingling. They grew well without inhibiting each other. There was formation of yellow pigment in colony of yeast which suggested that as the colony of Trichoderma comes in contact with yeast some reaction took place between them, but the inhibition of any colony was not found. Trichoderma and Bacillus inoculated in the same plate were found to be not intermingling with each other. Growth of Trichoderma colonies restricted at the point of contact of Bacillus. This result suggested the inhibition at the point of contact between Trichoderma and Bacillus. The interaction between Yeast and Trichoderma were found to be partial intermingling with each other without inhibiting each other. The plates inoculated with Trichoderma, Bacillus and Saccharomyces shows growth of all these micro-organisms without inhibiting any colony.

\section{DISCUSSION}

In this study the interaction between Saccharomyces cereviseae, Trichoderma viridae and Bacillus PU7 were investigated for compatible/incompatible mixed culture which will help in acceleration of bioconversion of domestic solid waste in to compost. When combinations of mixed cultures were counted for their total viable count, it was found that in mixed culture of Yeast and Trichoderma awamori, the total viable count of yeast was $14.5^{*} 10^{7} \mathrm{cfu} / 1 \mathrm{~m} 1$ and Trichoderma viridae was $4.14 * 10^{7}$ $\mathrm{cfu} / 1 \mathrm{ml}$. This result shows that there was declination in the count of yeast and Trichoderma viridae in mixed culture, but there was not dominancy of any one colony in comparison with the other one. Both colonies were mutually growing.
Total viable count of mixed cultures of Bacillus and Trichoderma were found to be $5.01 * 10^{7} \mathrm{cfu} / 1 \mathrm{~m} 1$, and $6.43 * 10^{7} \mathrm{cfu} / 1 \mathrm{ml}$.This result shows that Bacillus and Trichoderma count increased in mixed culture. Bacillus and Yeast were found to be $6.64 * 10^{7} \mathrm{cfu} / \mathrm{l} \mathrm{ml}$ and $3.75 * 10^{7} \mathrm{cfu} / 1$ $\mathrm{ml}$. These results suggested that count of yeast colony decreases but Bacillus count remain the same in mixed culture without hampering each other. Count of mixed culture of Trichoderma. Bacillus and yeast were found to be $6.48^{*} 107 \mathrm{cfu} / 1 \mathrm{ml}, 4.91 * 10^{7} \mathrm{cfu} / \mathrm{ml}$ and $8.86^{*} 10^{7} \mathrm{cfu} / 1 \mathrm{ml}$. The microbial changes during thermophilic composting of food waste were investigated at $50{ }^{\circ} \mathrm{C}$ using a laboratoryscale composter. The results showed that an early increase in the growth of yeast was followed by the growth of thermophilic bacteria, and that subsequently, the yeast declined rapidly. Trichoderma viridae and Trichoderma reese $i$ were used, separately and in mixed culture, to convert apple distillery waste into microbial biomass. Overall, the use of mixed culture had considerable advantages, the positive properties of each species being retained. The effect of Trichoderma is evident in improved filtration and chemical oxygen demand reduction, as well as in the 3glucosidase synthesis. Trichoderma, on the other hand, contributes to good fiber degradation, protein enrichment of the biomass and cellulolytic, xylanolytic and pectolytic activities in the filtrates.

\section{CONCLUSION}

Different in vitro interactions were studied. Saccharomyces cereviseae, Bacillus PU7 and Trichoderma viridae were in same Petri dish in their respective media. The interaction between Yeast and Trichoderma were found to be mutual intermingling. They grew well without inhibiting each other. There was formation of yellow pigment in colony of yeast which suggested that as the colony of Trichoderma comes in contact with yeast some reaction took place between them, but the inhibition of any colony was not found. Trichoderma and Bacillus inoculated in the same plate were found to be not intermingling with each other. Growth of Trichoderma colonies restricted at the point of contact of Bacillus. This result suggested the inhibition at the point of contact between Trichoderma and Bacillus. The interaction between Yeast and Trichoderma were found to be partial intermingling with each other without inhibiting each other. The plates inoculated with Trichoderma, Bacillus and Saccharomyces shows growth of all these micro-organisms without inhibiting any colony. According to above observation it was suggested that mixed culture of Yeast and Bacillus, yeast and Trichoderma viridae are showing best compatibility compared to Bacillus, Trichoderma, and yeast combination and Bacillus and Trichoderma. Compatible mixed culture of Yeast and Trichoderma, and Yeast and Bacillus PU7 were found to be very effective it accelerating decomposition of kitchen wastes.

\section{REFERENCES}

[1]. Hart SA, Newhall GN. Managing the wastes of farm and forest. In: Wilson DG, editor. Handbook of Solid Waste Management. Litton Educational Publishing, 1977. 
[2]. Martin A.M. Biological Degradation of Wastes. Great Yarmouth, GB: Elsevier Science Publishers Ltd, 1991.

[3]. Myles TG. Possible use of termites on spent mushroom substrate or other agricultural by products to: 'WASTE \{List\}' Bwaste@cedar.univie.ac.atl Subject: WASTE: Composting: Duckweed, Mushrooms, Earthworms, Termites, 2 May 1997. From: Tim Myles Bt.myles@utoronto.ca, 1997. 